This item was submitted to Loughborough's Research Repository by the author.

Items in Figshare are protected by copyright, with all rights reserved, unless otherwise indicated.

\title{
Do different training conditions facilitate team implementation? A quasi- experimental mixed methods study
}

\section{PLEASE CITE THE PUBLISHED VERSION}

http://dx.doi.org/10.1177/1558689815589050

\section{PUBLISHER}

SAGE Publications / @ The Authors

VERSION

AM (Accepted Manuscript)

\section{PUBLISHER STATEMENT}

This work is made available according to the conditions of the Creative Commons Attribution-NonCommercialNoDerivatives 4.0 International (CC BY-NC-ND 4.0) licence. Full details of this licence are available at: https://creativecommons.org/licenses/by-nc-nd/4.0/

\section{LICENCE}

CC BY-NC-ND 4.0

\section{REPOSITORY RECORD}

Nielsen, Karina, Raymond Randall, and Karl B. Christensen. 2019. "Do Different Training Conditions Facilitate Team Implementation? A Quasi-experimental Mixed Methods Study”. figshare. https://hdl.handle.net/2134/16706. 
Do different training conditions facilitate team implementation? A quasi-experimental mixed methods study

\begin{abstract}
A mixed methods approach was applied to examine the effects of a naturally occurring teamwork implementation supported with training. The first objective was to integrate qualitative process evaluation and quantitative effect evaluation to examine how and why the training influence intervention outcomes. The intervention $(\mathrm{N}=328)$ was supplemented with four training conditions (no training, team member training, team leader training and a combination of training types). The second objective was to examine whether different training conditions support team member training in isolation, but not in combination, led to positive outcomes. The integrated analysis of qualitative and quantitative data indicated that a number of contextual factors interacted with training experiences and outcomes to influence the success of team implementation.
\end{abstract}

Word count: 119

Keywords: Mixed methods, intervention, teamwork, multilevel, training, job crafting. 
A team can be defined as a group of people who share a common goal, and are jointly responsible for completing the tasks involved, i.e. high interdependency and autonomy (Sprigg, Jackson, \& Parker, 2000). Quantitative studies indicate that teamwork can have a positive impact on innovation, effectiveness, and employee health and well-being (Rasmussen \& Jeppesen, 2006). These outcomes have been attributed to the development, release and synergies of employees' potentials within teams (Yeatts \& Hyten, 1998). Therefore, teamwork has been implemented to reduce managerial control and to stimulate team members (Grant \& Parker, 2009; Combs, Hall, \& Ketchen, 2006). Compared to those in conventional work groups, employees in effective teams show more initiative, facilitate more on-going improvements in work practices, take more responsibility for independent decision-making, and engage more in innovative problem solving (Grant \& Parker, 2009; Joiner, 2007). In such environments, the role of first line leaders also changes from that of a delegator and organizer to that of a coach and facilitator (Elloy, 2005) with overall responsibility for teamwork implementation (Morgeson \& Humphrey, 2006). Therefore, implementing teamwork can yield significant benefits but it has implications for team members and team leader training. These employees may not have the resources to meet the new and different demands associated with teamwork (Nielsen \& Daniels, 2012; Nielsen, Randall, \& Christensen, 2010). There has been relatively little detailed field research into the effects of training when it is integrated with teamwork implementation (Salas et al., 2008). Much of the research on training newly forming teams has taken place in controlled laboratory or classroom settings partly because of the control over study design and the measurement of variables that this approach can offer. However, such research design has been criticized for lacking generalizability to phenomena that matter to organizations and their participants and for lacking external validity as it has been argued that they the extent to which the researcher succeeds in establishing the laboratory conditions necessary to confirm the research hypothesis rather than real-life phenomena (Grant 
\& Wall, 2009). Quantitative, effect-only evaluations of teamwork implementation with training, such as those included in the meta-analysis by Salas et al. (2008), show that factors such as team size and stability can influence the effectiveness of team training. Such studies are unlikely to unveil sufficiently detailed information about why such training may enhance team implementation processes in complex organizational settings and thus fails to inform future research and practice. Therefore, in this study, we integrated qualitative intervention process evaluation with quantitative outcome evaluation to examine whether training helped employees build the personal resources needed for effective teamworking (Hobfoll, 1989) and contributed to the subsequent crafting (Wrzesniewski \& Dutton, 2000) of important teamwork practices. In this naturally occurring quasi-experiment we have a unique opportunity to study the strategies that organizations use when implementing changes: The support offered to employees and managers in the form of training designed to encourage the implementation of teamwork practices. Using the theories of Conservation of Resources (Hobfoll, 1989), Job Crafting (Wrzesniewski \& Dutton, 2000) and Social Identity Theory of Leadership (Hogg, 2001), we examine the effects and mechanisms of four group combinations of training (no training, employee training only, team leader training only, and employee and team leader training in combination). The study design also allowed us to examine the impact of the organizational context on participants' training experiences and the intervention processes and outcomes.

At the methodological level, the study was designed to test whether mixed methods can enrich our understanding of the complex organizational change processes. The design allowed us to examine both how and why the training was linked to teamwork implementation processes and their outcomes. We strengthen causal inference by using a quantitative pre-post post controlled design to rule out alternative explanations and by employing qualitative methods to understand the results of the quantitative evaluation. At a job redesign level, we examined which, if any, of the four different training conditions facilitated team implementation to bring 
about positive outcomes. By using qualitative methods we were also able to capture and analyze data about the impact of the organizational and team contexts on the transfer of training (Johns, 2006). A few studies have examined training in a team implementation context (Cordery, Mueller, \& Smith, 1991; Morgeson, Johnson, Campion, Medsker, \& Mumford, 2006) but to the best of our knowledge, no single study has directly examined the effects of several different types of teamwork implementation training delivered to newly-formed teams in a naturally occurring quasi-experiment. This study was designed to add to the research literature by combining quantitative analysis of the effects of different training conditions with detailed qualitative descriptions of the translation of this training into changes in working practices. We thus address the call of Grant and Wall (2009) to conduct quasi-experimental experiments that have a high level of external validity (in that they study real-life phenomena)and that offer the opportunity to build better theories on naturally occurring phenomena, and we evaluate phenomena of high relevance to organization. Addressing the call of Noe, Tews, and Dachner (2010) to widen the perspectives of training transfer to also include the active role of trainees, we examined the extent to which knowledge and skills acquired during teamwork training were actively translated into everyday work activities: to do this we used Job Crafting theory (Wrzesniewski \& Dutton, 2010).

\section{The Impact of Team Interventions}

The implementation of teamwork places demands on employees that require employees to identify, develop and protect specific personal resources including the individual's ability to successfully control and impact upon their environment (Hobfoll, 1989). For example, when employees become jointly responsible for completing a task they must interact in a different way to support each other to complete this task (Joiner, 2007; van Mierlo, Rutte, Kompier, \& Dooreward, 2006). Typically teamworking is also associated with high levels of individual autonomy in decision-making, task planning and task completion (Joiner, 2007; van Mierlo et 
al., 2006). Enhanced social interaction and autonomy represent organizational resources that are made available to employees through the exposure to teamwork practices (Joiner, 2007; van Mierlo et al., 2006). These two factors appear to be key drivers of the high levels of effectiveness and employee involvement frequently found in successful teamwork (Rasmussen \& Jeppesen, 2006).

Job crafting, "the physical and cognitive changes individuals make in the task or relational boundaries of their work" (Wrzesniewski \& Dutton, 2001, p. 179) can be used to explain how employees use the organizational resources of autonomy and social interaction to craft their jobs newly formed teams. Through job crafting, individuals actively strive to shape a job role in which they can use their skills (Tims \& Bakker, 2010) and mobilize resources to fulfil their needs and thrive at work (Demerouti, Bakker, Nachreiner, \& Schaufeli, 2001). Research suggests that employees proactively shape work tasks and the kind of support they seek (Petrou, Demerouti, Peeters, Schaufeli, \& Hetland, 2012). These are important skills in teamwork settings (Morgeson \& Humphrey, 2008). Autonomy of the kind provided by properly implemented teamwork is a precondition for job crafting (Leana, Appelbaum, and Shevchuk, 2009; Wrzesniewski \& Dutton, 2001) and may allow employees and leaders to job craft their working practices according to the principles of teamwork.

\section{Training Team Members as part of Team Implementation}

Effective teamwork requires a range of knowledge, skills and abilities concerning conflict resolution, collaborate problem solving, and communication (Morgeson \& Humphrey, 2008): these are skills that employees do not always possess. Conservation of Resources (COR) theory indicates that employees are highly motivated to protect and develop resources during a period of change at work (Hobfoll, 1989). COR suggests that successfully dealing with new demands is only possible if one has or gains the personal resources necessary to deal with these new demands. Organizational resources such as autonomy and social 
interaction may be made available through teamwork, but may remain unused if team members do not have the personal resources to take advantage of them. The introduction of teamwork without accompanying training could result in a mismatch between the individual's personal resources and the demands of the environment with lack of involvement and poor performance as the result (Demerouti et al., 2001; Hobfoll, 1989). It could also mean as teams are not implemented according to plan core characteristics of teams, autonomy and interdependence, do not materialize. We predict that training designed to develop team members' resources to deal with the demands of teamwork may tackle this risk and promote interdependence, autonomy, involvement and improved performance (Thomas, Whitman, \& Viswesvaran, 2010). Previous research has found that employees who possess a wide range of personal resources are more likely to engage in the type of job crafting stimulated by teamwork (Kira, van Eijnatten, \& Balkin, 2010). In addition, Leana et al. (2009) found that involvement in collaborative job crafting activity stimulated team members to work together to change work practices and processes.

Training team members together may facilitate successful team implementation (Noe et al., 2010). Shared mental models have been defined as "knowledge structures held by members of a team that enable them to for accurate explanations and expectations for the task, and in turn, coordinate their actions and adapt their behavior to demands of the task and other team members" (Cannon-Bowers \& Salas, 2001, p. 228). The development of shared mental models through training may be especially important when team implementation involves inexperienced employees or those with relatively little formal education. Smith-Jentsch, Campbell, Milanovich, and Reynolds (2001) found that lower ranking employees that had limited time in the service had less accurate shared mental models of how to work in teams. In addition, Mathieu, Heffner, Goodwin, Salas, and Cannon-Bowers (2000) found a link between team members and effective team performance. Therefore we predict that training employees to 
develop shared mental models of teamwork will be effective in the elder care organization in our study because participants have little formal education or experience of teamwork. More generally, team training can enhance teams' reflexivity (the ability to critically reflect on their working practices) and understanding of teamwork principles thus leading to better performance (Gurtner, Tschan, Semmer, \& Nagele, 2007).

Hypothesis 1: Specific teamwork implementation training for members in a team will bring about increases in team interdependence, autonomy, effectiveness, and employee involvement. These effects will be over and above those found in teams where training is not used.

\section{Training Team Leaders as part of Team Implementation}

It is well-documented that supervisors play an important role as coaches and facilitators during teamwork implementation has been identified (Nielsen \& Daniels, 2012; Senior \& Swailes, 2004). However, even if such a role is assigned this does not guarantee that leaders' behaviors will change (Fuller, Marler, and Hester (2006). The introduction of teamwork may result in an imbalance between the leaders' personal resources and the demands they face (Nielsen \& Daniels, 2012). The application of COR theory (Hobfoll, 1989) indicates that training may help leaders obtain and protect the necessary personal resources and help to make them feel in control and able to cope with the demands of implementing teams (Golhar, Dashpande, \& Ahire, 1997).

As with team members, using training to communicate to team leaders the benefits of teams, their future role, and to provide them with new knowledge and skills may encourage them to job craft (Parker \& Williams, 2001). It may also encourage them to persist with the implementation of teamwork practices in the face of significant contextual challenges (Nielsen et al., 2010). 
Therefore, we argue that providing first line leaders with competency-based training on how to implement and manage teams will increase the likelihood of them facilitating team implementation by both crafting their own new role and by supporting team members to implement the change.

Hypothesis 2: Training team leaders alongside the teamwork intervention will bring about significant additional positive changes in team interdependence, autonomy, effectiveness, and employee involvement.

\section{Combining Employee and Team Leader Training}

Social Identity Theory Of Leadership (SITOL, Hogg, 2001) suggests that a group of employees who perceive their team leader to share their norms and values (the prototypical leader) are more likely to engage in the behaviors advocated by this leader (Haslam \& Platow, 2001; Hogg, 2001). This is consistent with research showing that the impact of teamwork is stronger when team members see team leader behaviors as being consistent with their own self-concepts (Gilpin-Jackson \& Bushe, 2007). Training team members has been found to improve attitudes towards their leaders (Osland, 1997) and Nielsen and Daniels (2012) found that when the team leader and team members shared a perception of teamwork implementation as useful and within the established norms of the group, they were more likely to jointly work towards implementing the intervention.

Leaders have also been found to be important role models who can promote desired behaviors in teams (Bass \& Riggio, 2006). When team leaders exhibit behaviors consistent with effective teamwork, team members may be more likely to also model that behavior. Recent meta-analysis and reviews have identified line manager support as one of the most important predictors of training transfer (Blume, Ford, Baldwin, \& Huang, 2009; Burke \& Hutchins, 2007; Salas, Tannenbaum, Kraiger, \& Smith-Jentsch, 2012). 
Leaders' behavior can also play an important role in the transfer of training. For example, transfer may be limited when trainees are not held accountable for applying what they have learned on the training course to daily work practices (Burke \& Saks, 2009). Training both team leaders and team members in how to implement and work in teams may result in accountability and more effective transfer. This leads to our third Hypothesis:

Hypothesis 3: The greatest impact of training on the positive outcomes of teamwork occurs when both the leader and the team members receive training.

\section{Exploring the Importance of Training Context: Conducting Process Evaluation}

Mixed methods in evaluation research goes beyond traditional notions of effectiveness to explore intervention acceptability, the quality of intervention implementation and the application of the intervention in daily life (Nastasi, Hitchcock, Sarkar, Burkholder, Varjas, \& Jayasena, 2007). To reflect the complex real-life phenomena of organizational change and to investigate the many possible effects of different training conditions on teamwork implementation we chose to integrate a qualitative intervention process and context evaluation with a quantitative intervention outcome evaluation in this quasi-experiment. There were three reasons for this. First, it has been argued that disappointing team intervention outcomes may be due to poor implementation or a hindering context (Bambra, Egan, Thomas, Petticrew, \& Whitehead, 2007; Nielsen et al., 2010). To test the study hypotheses we needed to isolate the effects of the teamwork intervention in order to better understand the impact of the training and to explore the interactions between the two in light of the organizational context. Second, organizational constraints meant that it was not possible to allocate teams at random to different training conditions: This is a common problem in organizational intervention research (Richardson \& Rothstein, 2008). When random allocation is not possible, outcome-only evaluation methods do not yield sufficient data to illuminate change processes (Semmer, 2006). Third, understanding the relative impact of i) team implementation, ii) the team member 
training, iii) the team leader training, and examining iv) the interactions between them was likely to involve the examination of many constructs in complex mechanisms. In their reviews, Burke and Hutchins (2007) and Salas et al. (2012) concluded that training transfer can be affected by the complex interplay of both individual characteristics (e.g. self-efficacy, mastery goal orientation, motivation and perceptions of utility/value) and the prevailing organizational context (e.g. structured opportunities to use and practice new skills, peer and first line leader support and accountability). Recent reviews of organizational interventions (Nielsen \& Randall, 2013) and training transfer (Grossman \& Salas, 2011) have suggested that a three-level process evaluation model is needed: This can be used to capture data about the (training) intervention, participants' attitudes and mental models and the context. Therefore, we developed a research question that required a mixed methods approach:

Research question: How does exploring the context, individual attitudes, and job crafting activities, team implementation processes help us understand the effects of the intervention that appear in the quantitative outcome evaluation?

\section{Methods}

\section{Design}

This longitudinal study of teamwork implementation was conducted in a local government organization elder care department. We used an embedded quasi-experimental design (Creswell \& Plano Clark, 2007). Data were collected from four groups of participants (no training, team member training, team leader training, and combined team leader and team member training). Qualitative data was collected 15 months after baseline and three months before follow-up. This timeframe was used to gather data during the process of intervention after a sufficient period had elapsed to allow participants to provide comprehensive data on their experiences. We integrated quantitative survey data with organizational material (e.g. updates in the company newsletter and material handed out to leaders and employees), 
documentary evidence of team leader and team member involvement in intervention meetings (meeting minutes), and interviews and focus groups (with team leaders and team members) near the end of the intervention evaluation timeframe. We treated teams where no training was received as the reference group and compared them with teams where training was delivered at the request of the team leaders and team members. Table 1 provides an overview of participants' involvement in training. We expected that after the intervention all groups would score higher (better) on team outcome measures with additional benefits for the teams that had participated in training.

A questionnaire survey was distributed to both team leaders and team members immediately before (time 1) and after training (time 2) with an 18-month interval. This contained self-report measures of interdependence, autonomy, team performance and involvement.

Insert Table 1 around here

\section{Data sources and participants}

At the beginning of the research, elder care staff were organized into geographical units each providing community-based or residential care to elderly people. Therefore work groups were either community-based staff working across a specific geographical area or employees working in a specific part of a residential nursing home. Both types of unit participated in this study along with a small group of administrative staff and a small group of physiotherapists. All work groups had a formal first line leader who worked outside the group and held managerial responsibilities: This was the leader who participated in team leader training.

Before the team implementation group sizes ranged from five to 35. As part of the intervention, the biggest work groups were divided into smaller teams. For example, groups of staff who previously covered a large geographical area or a whole section of a care home would be split into smaller teams each covering either a smaller number of clients or specific work hours (e.g. 
two day-shift teams and one night-shift team). Post team-implementation, the largest sub-teams would have 13 members, and the smallest three members. In total 14, team leaders and their team(s) are included in our analyses (see table 1).

At time 1, the questionnaire was distributed to 349 employees, with 277 returned (response rate $=79 \%)$. The average age of participants was 43.1 years $(\mathrm{SD}=11.26)$ and $92 \%$ were female. The majority of staff (54\%) were healthcare assistants, $10 \%$ were nurses, $17 \%$ had other health-related educational qualifications (e.g. physiotherapists) and the remaining had no healthcare-related education (e.g. cleaning, canteen and maintenance staff). At time 2, 18 months later, the questionnaire was distributed to all 310 staff employed, with 152 returned (49\% response rate). At each round, employees were given 45 days to respond and were sent two reminders. Of these staff, $92 \%$ were female and the average age was $43.96(\mathrm{SD}=11.48)$. As at time 1, the majority of staff were healthcare assistants (53\%), 14\% were nurses, $10 \%$ had other health-related educations and the remaining had no healthcare-related education. In total, survey data from 328 employees was used. Of these, 101 participants completed the questionnaire at both times. Examination of company records indicated that at both time 1 and time 2 the employee samples were representative of the available study population in terms of gender, age and profession. Table 1 shows the number of participants who elected to join each of the training groups.

All team leaders $(n=14)$ were interviewed individually. Team leader interviews lasted from 25 to 60 minutes $(M=44.5)$. Randomly selected team members $(n=31$, at least two from each team) participated in ten focus groups (between 2 and 7 employees participated in each focus group). Interviews were transcribed verbatim and lasted from 34 to 68 minutes ( $M=49.8$ minutes).

\section{The Intervention}


Senior management made the decision that all elder care centers would implement teamwork with some degree of self-management. The stated objectives were to implement teamwork to make full use of all employees' competencies, to ensure employee involvement and to empower employees to make independent decisions concerning their work with appropriate team leader support. As part of the intervention, leaflets were distributed to participants in which a team was defined as "a group of people who have a joint task to solve, they share a joint responsibility for solving the tasks and within the team there are defined roles and team members depend on each other to solve the task". This definition was designed to convey to the participants the objectives of the training in a way that was consistent with scientific definitions of teams (e.g. Cohen \& Bailey, 1997). In the leaflet it was also stated that team leaders would play an active role in supporting teams and the leader's new role was described as moving from "oracle to coach", meaning that the role was no longer to be the expert but to facilitate reflection and decision making. An elder care center leader worked as a full-time consultant to facilitate the intervention process because she had previously implemented teamwork. At the beginning of the implementation process, elder care center managers participated in an interactive briefing about team organization that was designed to improve their knowledge about the key ingredients of teamwork as identified in the scientific literature (i.e. autonomy, interdependence, involvement and effectiveness). The consultant then held after-work meetings where both team leaders and employees discussed the potential advantages and the challenges associated with teamwork. To further develop and cement participants' knowledge of teamwork, the personnel magazine frequently included user-friendly articles and updates about team organization. In an effort to improve participants' knowledge of the practical steps they could take during the intervention, a self-help booklet describing how teamwork could be implemented and maintained was distributed to all members of staff. 
The formation of teams was designed to make employees within each team (i.e. team members) jointly responsible for a group of clients. These teams dealt with two types of tasks: those originating directly from clients and those that were determined by the team leader. Team members were made responsible for allocating tasks between them and for deciding how these should be completed: they were encouraged to take over a number of managerial responsibilities (such as the planning of work schedules and contact with clients, their families, and suppliers). Regular scheduled team meetings were introduced where team members would share knowledge and experiences and devise alternative ways of solving problems. To support and cement these changes team leaders' responsibilities in the new teams were redefined to become focused on communicating a vision for the future, ensuring involvement in decision making, and supporting team learning.

The team leader and team member training were different in order to reflect the different roles of the two groups of staff. Team leaders received training on how to implement, facilitate and coach teams: This was designed to support them in making the transition from "oracle to coach". In contrast, team members received training on how to develop their own and their team colleagues' resources by collaborating effectively with others in the planning and execution of work tasks. To facilitate deep learning and training transfer both courses used an action learning approach (Revans, 1971; Raelin, 1994) focusing on encouraging participants to use in their workplaces the explained during the training course (e.g. methods of conflict resolution, the ground rules for good interaction, tools for structuring teams and for participating in team activities in ways that members had a high degree of autonomy).

Due to financial constraints, these were off-the-shelf team training courses each provided by a different external provider. Full information about the training courses can be obtained upon request from the authors. 
Team leader training course. The offer to participate in this training was made to all team leaders: seven participated. Training was delivered across eight separate days ending with a written and oral knowledge exam. The training included topics designed to develop both knowledge about, and attitudes to, team working. More specifically, modules covered: the team leader's role as a facilitator of worker interdependence, autonomy and involvement; techniques for facilitating and managing both individual and team development in ways that promoted team effectiveness through autonomy, interdependence and involvement; techniques for translating leadership and teamwork theories into daily work practices; the development of interpersonal competencies necessary to coach team members and active problem solving. Employee training. The offer to participate in this three-day training course was made to all team members: eight teams participated. Whole teams participated but only if there was a consensus within the team to accept the offer. It has been argued that to be effective teams should receive training as a whole in order to effectively stimulate coordination, communication and cooperation in a team environment (Kozlowski \& Bell, 2003). Much of the training focused on developing team resources through these three mechanisms. With one exception (described in Results), team leaders did not participate in training. The training was also designed to convey knowledge about the characteristics of good teams (i.e. interdependence, autonomy and involvement) and the factors that made them function. Team members participated in team building exercises in which they made joint decisions; these were designed to facilitate deep learning about effective team processes and to help participants develop the resources needed for collective job crafting. Subsequently, trainees were encouraged reflect on their collaborative working practices and how these could be transferred to daily work. Team members also completed activities that required them to develop both ground rules for good interaction (to enhance their understanding of the importance of social support) and team goals (to facilitate the identification of shared objectives). These activities 
were designed to raise awareness of the importance of mindful interaction, to foster collective job crafting, to increase collaboration among team members, and to facilitate constructive resolution of conflicts between team members.

\section{Measures: Outcome evaluation}

Team interdependence. This was focused on the degree to which team members reported that they had to work together to complete their tasks. This was measured using a fouritem scale adapted from Sprigg et al. (2000). An example of an item was "members of my team have skills and abilities that complement each other". Participants rated interdependence on a scale from 1 (strongly disagree) to 5 (strongly agree). Cronbach's alphas were .80 (time 1) and.78 (time 2).

Autonomy and team effectiveness. Autonomy was measured using an adapted five-item scale from the TPI (Team Performance Inventory, West, Markiewicz, \& Dawson, 2004) and focused on the perceived degree of team freedom to determine how to complete tasks and the level feedback enabling task completion. An example item was "we decide as a team who will do what in the team". Team effectiveness measured the extent to which participant perceive the team to be praised for the quality of its work and exceeds its goals. It was measured by three TPI items including "the team is consistently told that it achieves or exceeds its goals". On both scales participants reported their perceptions on scales from 1 (strongly disagree) to 5 (strongly agree). Cronbach's alphas for autonomy were .79 and .78 at time 1 and time 2 respectively. For team effectiveness Cronbach's alphas were 69 (time 1), and 72 (time 2).

Involvement. This was measured by a four-item scale taken from the COpenhagen PsychoSOcial Questionnaire (COPSOQ; Kristensen, Borg, Hogh, \& Hannerz, 2006). An example of an item is "do you feel that your place of work is of great personal importance to you?" The scale was from 1 (to a very large extent) to 5 (to a very small extent). Cronbach's alpha at time 1 was .71 , and .85 at time 2 . 


\section{Analyses}

Transformations. All scales were transformed so they ranged from 0-100 with 100 representing a high score on the construct. Responses were transformed such that $1=0,2=$ $25,3=50,4=75,5=100$. This was done facilitate interpretation of results at the descriptive level and does not influence the outcomes of the data analysis (Nielsen et al., 2010).

Hypothesis testing. We used multilevel analyses for a number of reasons. Our design had two levels of nesting: first, our longitudinal design and second, our individuals within teams. Therefore, we analyzed data from individuals nested within teams, and from measurement occasions nested within individuals. Multilevel analyses allowed the use of data from the dropout cases (Bryk \& Raudenbusch, 1992). This strategy helped to retain power in the analysis and to draw upon data from representative samples at both measurement points. The important assumption that missing data was random appeared to be justifiable because the demographic profiles of those providing data at time 1 and time 2 were comparable indicating the absence of systematic non-responding biases.

At baseline there were significant between-team differences on all four measured variables: these pre-intervention differences were controlled in the analysis. The overall sample size was relatively large, but the inclusion of four different exposure groups meant that some of the groups were relatively small. Small sample sizes are common in intervention research (Nielsen, Fredslund, Christensen, \& Albertsen, 2006). We interpreted change as being significant at $\mathrm{p}<.05$. However, because of the small sample size in some groups and many factors that have been shown to influence team outcome measures, there was an increased risk of type II error (Freiman, Chalmers, Smith, \& Kuebler, 1978). Therefore we also include a tentative discussion of effects significant at $p<.1$ but only when evidence from the process evaluation provided a logical rationale for considering these smaller effects.

\section{Analysis framework: Process Evaluation}


The results of previous research on process and context evaluation (Nielsen et al., 2006; Nytrø, Saksvik, Mikkelsen, Bohle, \& Quinlan, 2000; Saksvik, Nytrø, Dahl-Jørgensen, \& Mikkelsen, 2002) and current evaluation frameworks (Grossman \& Salas, 2011; Nielsen \& Randall, 2013) were used to construct semi-structured guides for the focus groups and interviews and we content-analyzed the training. Interview guides followed the themes of intervention (training) design, individual factors, and context. These activities allowed us develop new data collection tools that focused on the hypothesized working mechanisms of the interventions (both teamwork and the associated training activities) and the impact on both of the prevailing organizational context. Interviews were coded in QSR NVivo and template analysis (Patton, 2002) was conducted based on three themes (Grossman \& Salas, 2011; Nielsen \& Randall, 2013):

1) Description of the intervention activities and their implementation. This involved exploring the degree to which participants in training felt they had learned something they could use and how this learning was translated into job crafting teamwork practices (Burke \& Hutchins, 2007). We asked employees and leaders to describe the team activities that had taken place during the implementation phase.

2) Team leaders' and team members' mental models. Data were collected on how team leaders and team members perceived, understood, and remembered the intervention process (Pettigrew, 1990). Mental models theory (Druskat \& Pescosolido, 2002) was used to explore how leaders and teams perceived managing, and working teams. We asked participants how they saw the role of the leader and the team members in team implementation and whether they saw themselves as a (well-functioning) team.

3) Intervention context. Previous studies have shown how the context-downsizing, restructuring, layoffs, and leader turnover - has an impact on both the interventions themselves and intervention outcomes (Nielsen et al., 2006; Saksvik et al., 2000) and on training transfer 
(Burke \& Hutchins, 2007). We therefore asked employees and leaders to identify factors in the context that may have hindered and facilitated team implementation. We developed a question protocol to collect these data and allow rigorous analysis. Full information about the interview guide and the coding in NVivo can be obtained upon request from the authors.

\section{Results: Outcome Evaluation}

Table 2 shows the results of the quantitative outcome evaluation using multi-level analyses. In our no-training reference group (group 1) we expected increases (improvements) in team outcomes due to the implementation of teams. However, for 2 out of 4 outcome measures decreases were found. After the implementation of teams, employees in the reference group perceived their team to be less effective and reported being less involved in their job.

In group 2 (team member-only training) we expected increases in the four outcome measures above those of our no-training reference group (Hypothesis 1). There was good support for this prediction: there were significant increases in team autonomy, and team effectiveness, with a trend towards increased interdependency $(p<.10)$. When comparing these changes with the reference group (group 1) we found those in group 2 reported significantly higher autonomy $(t(306)=2.36, p<.05)$, team effectiveness $(t(285)=3.15, p<.01)$ employee involvement $(t(366)=2.34, p<.01)$, but a smaller difference in team interdependency $(t(278)$ $=1.78, p<.10)$ than the reference group.

In group 3 (team leader-only training) we also expected increases larger than those reported in the reference group (Hypothesis 2). This Hypothesis was partially supported. Two changes in group 3 were significantly higher than those found in the reference group. These were increased interdependency $(t(278)=2.73, p<.01)$ and team effectiveness $(t(285)=2.34$, $p<.05)$

In group 4 (both team member and team leader training) we found no support for the Hypothesis that training all participants would have the most positive outcomes (Hypothesis 3). 
From time 1 to time 2 we found a tendency for a significant increase in team autonomy but the remaining outcome measures remained stable (see Table 2). This group improved significantly above the reference group only on employee involvement $(t(366)=2.19, \mathrm{p}<.05)$.

Insert Table 2 around here

Summary of outcome evaluation. The no-training reference group remained stable or experienced some negative changes over the intervention period. Previous research on the implementation of teams suggests that positive change should have occurred even without the training intervention. In all training groups there were significant improvements found above those in the reference group. These results suggest that without training team implementation may fail. There was more evidence of impact when the two training interventions were delivered in isolation (supporting Hypotheses 1 and 2).

\section{Results: Process Evaluation and its Integration with Outcome Evaluation}

\section{Overall evaluation of the training courses: Common findings}

In interviews and focus groups, many team leaders and team members reported that the training courses had been useful. All team leaders felt that the tools provided on the training course had helped them to introduce teamworking and that the training course had given them an opportunity to discuss their experiences with implementing teams with peers. Team members reported that it had taken some time for them to understand how learning from the course could be translated into work practices. However, as the training developed they had become increasingly aware of how they interacted as a team. During interviews they reported that they had begun to adhere to the ground rules developed on the training course and that they transferred what they had learned during the training course to daily work. The different experiences reported by participants from each of the four study groups are described below. In reporting these findings we integrate the qualitative process evaluation with the quantitative outcome evaluation. 


\section{Group 1: Reference Group, No Training (5 Teams)}

Team activities and their implementation. Only in one team had changes taken place: This very limited amount of change provided preliminary evidence for the importance of the training intervention. In this one team, members were now responsible for planning meetings and the roster. However, in this team the team leader had gone on long-term sick leave and the team felt they could not progress without her and team implementation had stagnated: “...Our framework has become fragile because she [the team leader] was good at setting the framework concerning the things we could or should do. I feel that the framework is slipping. We don't have this: Is it you or us that should do this? You shout in the forest but you get no response....I can feel it is difficult to be without a team leader...Many questions arise that are not taken care of." (Employee \# 3, Team 2)

Employees and team leaders in the remaining four teams reported using cognitive job crafting to develop a situation where no action was taken to implement teamwork: They reported they already worked in teams and that the intervention was therefore not relevant to them.

"We already worked as a team, we were a group. There is a difference but the problem is to figure out what the difference is.....I still feel like the chief around here." (Leader \# 1, Team 1). "We do exactly how we have always done. Because we work in teams - that we have done all the years I have been there...to be honest I didn't really pay much attention to the team thing because when they explain to us what it is, then we just say: 'We already do that'. So I don’t think we dig any deeper into it and think about what it means to be a team." (Employee \# 9, Team 5). These comments offered a clear explanation of the reasons underlying the choice to not attend the training offered to team leaders and team members.

Mental models of leaders and employees. Employees reported being skeptical about the introduction of teams, believing there to be a hidden agenda of management i.e. that team 
members would pressure each other to come to work to reduce absenteeism. Employees felt teamwork did not bring added value to the services provided to clients but instead meant they had less time to provide a good service. Employees also expressed little interest in taking on further responsibilities that they felt the leader was paid to hold:

"Planning rotas and deciding on holidays, that is the leader's job. It is what she gets paid to do." (Employee \# 6, Team 3)

Leaders shared the negative view of teamwork and few had made any progress in delegating tasks to employees:

"Because I am the one with the time to do it, if they have to do it they have even less time to work with the clients (Leader \# 10, Team 5)

Many team leaders and employees in this group also perceived team implementation to be yet another "management fad" (Employee \# 6, Team 3). However, some employees in the group felt frustrated that team leaders had not taken the initiative in implementing teams or were not clear about the role of the leader in the team structure and they perceived they had little opportunity to drive this change without the leader.

"We don't have time for meetings and team implementation. There is no framework for teamwork....we have requested going on training - to get some education on what is a team and how do we create a team but there is no money for it because we are therapists and we already have an education... What is difficult is that when you are in a team you have no leader, so when you have to say something to the team, no-one wants to take responsibility." (Employee \# 10, Team 5)

Intervention context. In this group the context had played a major role in determining the degree of team implementation. It had been difficult to retain and recruit staff and positions had been vacant for long periods. Team leaders reported a lack of support from the local center leader in implementing teams. During the team implementation phase, it was announced that 
there would be staff redundancies. Several managers linked this with their reluctance to relinquish control over the delegation of tasks.

One leader explained it this way:

"My evening shift is budgeted to DKK 300.000 a year but they cost DKK 375.000. So it is normal maths when we run out of money. And that doesn't facilitate team implementation....We have to cut down on staff. And that means you go back to the old ways. It is so easy to delegate all tasks to me.” (Leader \# 3, Team 3)

Together these data led us to conclude that these five teams may have, in part, selfselected themselves into the no training condition and, in part, been constrained by circumstances from implementing the intervention. The integration of the process and outcome evaluation indicated that the worsening of working conditions in this group was more likely to be driven by negative contextual factors than by the lack of exposure to the intervention.

\section{Group 2: Employee Training (2 Teams)}

There were very diverse experiences of the intervention process within this group. In one team, the first line leader had taken a sabbatical. Although a nurse had been officially appointed team leader, she played no active role in managing the team. As a result the team had divided itself into two sub-teams and each team had selected a team member to be responsible for implementing teams, in effect acting as team leader. In one of these sub-teams, a female team member who was implementing the team went on the team member training course with her colleagues. In the other sub-team, a male peer was appointed, but he did not participate in team member training. In the other team, the team members received training without their leader being present.

Intervention activities and their implementation. Team members of the first sub-team (with the female team leader) reported that they had developed a psychological contract about collaboration and co-operation within the team thus crafting a framework for relational 
interaction. They had crafted their jobs such that they were now jointly responsible for planning the daily work and the roster. The team members had carried out an analysis of some managerial tasks that were not part of daily work and each employee assumed responsibility for at least one of these tasks. There was good evidence that they had used the resources acquired on the training course to craft their job tasks and interpersonal relations according to the principles of teamwork. In the second sub-team (with the male leader) no such initiatives were implemented. In the second team (the administration workers), it was reported that there had been no activities nor had changes in procedures taken place.

Leaders' and employees' mental models. The female "unofficial" team leader and her team members felt they had benefited from the course and they had acquired skills and resources on how to implement teams. This employee was reported to have assumed a natural team leader role: the team accepted her as such and perceived her to be a team leader who was committed and many changes were implemented, with strong support from team members. In contrast employees in the other sub-team reported that they wanted a strong leader taking control and that the training course had not changed this perception. They had little interest in the teamwork intervention and working in teams. The male "team leader" reported he had little idea what to do and had made little attempt to change existing working procedures. In the second (administration) team, the team leader felt it had been difficult to work with team implementation as the team consisted of two recently merged work groups, each with a very different culture: team members reported that the leader seemed confused about how to implement teams.

Intervention context. Also in this group there were widely held views that the organizational context impacting on Group 1 had hindered team implementation. The barriers reported were eloquently summarized by one team leader: 
"We made a plan for what was going to happen and... and we had to change it all the time. So the process have meant....that you cannot make a plan for 'this is what we want to do' and you have to stray off that path all the time, and you have to be ready to change content and form and what we talk about and what is all this about all the time.” (Leader \# 8, Team 8)

Overall, the qualitative data offered insight into the effects found in the team member training group. The positive changes observed for this group in the outcome evaluation were linked to the very proactive approach taken by the leader and team members within one subteam. Within this team there was evidence that the training helped to empower a newly appointed team leader to initiate and maintain teamwork practices. The absence of a formal, established leader appeared to create a fertile context for the implementation of teamwork but only because the new team leader had preparatory training.

\section{Group 3: Team Leader Training Course (1 Team)}

Intervention activities and their implementation. In this team, employees had been split into two sub-teams that were each responsible for a smaller group of clients and were now responsible for planning team meetings. Team members reported they had become responsible for the roster, and several teambuilding initiatives had been initiated. They also reported that they had been given much more direct responsibility for patient care.

Leader and employee mental models. The team leader welcomed the team idea and was aware of her role in developing the team and its members. The team leader reported a lack of support from more senior managers but she thought this lack of senior level involvement gave her free rein to craft her role as team leader and the team structure as she wanted. She indicated that the training course had given her ideas as to how to implement teams and had inspired her to implement additional activities which may indirectly support team organization. It would thus appear that the training had given her personal resources to implement teams.

When asked about what employees liked about teamwork, one employee put it this way: 
"But I strongly think it is that you have a shared goal, that you have a shared set of values. You pull in the same direction. That is everything. It is no use that everyone is pulling in different directions, that has no effect." (Employee \# 12, Team 6).

Intervention context: Participants from this group reported similar organizational turbulence as in other groups (i.e. financial pressure and job uncertainty). However, rather than seeing the context as a hindrance they felt working in teams helped them cope with the turbulence:

"I like the way we work now. I think we have a really good team, we are good at supporting each other, especially now that we are run so tightly (financially), and at the end of the day I like this." (Employee \# 11, Team 6).

The findings from the process evaluation provided clear explanations for the positive changes in interdependence and effectiveness identified in the quantitative outcome evaluation: there was also good evidence that these changes had been directly stimulated by the transfer of learning from the training course. The qualitative data indicated that the modest changes on other measured variables could be due to the interaction of the turbulent organizational context with the teamwork intervention.

\section{Group 4: Combination of Employee Training and Team Leader Training (6 Teams)}

Intervention activities and their implementation. In five out of the six teams the group of employees been divided into two sub-teams as part of the intervention. All teams crafted their jobs such that team members were now responsible for the roster and work planning. All reported having regular team meetings.

Leaders' and employees' mental models. The team leaders' mental models revealed that they saw their teams as competent and they were aware of their role as supporting the team. The team members' mental models supported this. Most teams saw the team leader as supportive of them and team implementation and all felt they worked well together. 
"It is those values (working together) that form part of being a team. You can have those in a group as well in a team too, sometimes. But I can see that the basis for more development is greater in a team. And involvement of other resources and supporting each other and all those things... It has something to do with joy of working and synergy effects." (Employee \# 21, Team 10)

One of the leaders expressed it this way:

“They [team members] assume responsibility; they do a lot of things themselves. I really think they do. I can feel that at time goes and they become better and better at supporting each other then I am further away. Really, it is not like in the beginning I was here. Back then it was 20 questions to the professor. It is not like this anymore.” (Leader \# 20, Team 10)

However, two teams reported that older employees had found the transition difficult. There appeared to be significant problems with implementation in these teams.

"Many (older employees) are worried about new things. They feel better about stability.....When you want to introduce something new they don't think it is an advantage to them (Leader \# 14, Team 14)

Intervention context. The context was widely reported to have hindered team implementation. It was perceived that senior management was not supportive of team implementation and took little or no interest in supporting the change. Leaders and team members reported that the current structure did not support team organization and senior management showed little commitment to adjusting the current structure to fit team organization.

“I miss someone to spar with. I don't get that from my manager... It means so much that you as a team leader know where we are going and that hasn't been clear to me...I feel I have been on my own...What are we working with? What is the goal and where are we going?" (Leader \# 12, Team 12) 
One team had experienced significant redundancies (10\% of staff) and found it hard to invest time in team implementation under these circumstances:

“The savings catalogue [the plan for lowering spending] hasn't been much fun. Also that in relation to the savings catalogue we had to merge with another elder care center. That creates turbulence.” (Leader \# 13, Team 13)

Another team had been without a leader for a couple of months and, like in group 1, implementation had come to a standstill as the main driver of change had disappeared.

Summary of process evaluation. It was reported that there were significant barriers to implementation in some teams (e.g. resistance by employees with long tenure) and a perception that concurrent change presented significant challenges to team implementation. These appeared to disrupt some of the potential synergies offered by teamworking. Despite these difficulties there were reports of changes in management and employee behavior without there being extensive reporting of attempts to craft a job characterized by teamwork practices.

\section{Discussion}

This study reported the findings of an embedded quasi-experimental study of the effects of supporting team implementation with team member and team leader training. It offers a unique opportunity to understand the mechanisms and effects of a naturally occurring organizational change in a Danish eldercare. We integrated novel qualitative intervention process evaluation methods and established quantitative outcome evaluation methods to evaluate better the competing explanations for the results of this very complex, multifaceted intervention.

\section{The Impact of Training: Facilitating Team Implementation}

Without training, team implementation showed no improvements in outcomes and in some cases even had a detrimental effect. The results of the quantitative outcome evaluation, coupled with the application of COR theory (Hobfoll, 1989) could indicate that when 
employees do not have sufficient personal resources, teamwork implementation is more likely to fail. However, the mixed methods approach utilizing analysis of the process evaluation data revealed that that employees in the 'no training' group were not required to implement new teamwork practices due to an unfavorable organizational context and because of employee and team leader resistance to change.

Our results indicate that employees and team leaders in the reference group engaged in passive cognitive job crafting (Wrezniewski \& Dutton, 2001). This cognitive activity included the adoption of mental models that conceptualized change as being impossible or as having negative consequences. When absenting themselves from training those involved in implementing teamwork in a turbulent context perceived teamwork as a threat that was best avoided. Employees in the non-training group reported that they had no desire to change their procedures as they felt these were already working well. A similar finding was found by Vancouver and Kendall (2006) who found that during change high self-efficacy was negatively related to performance and motivation suggesting that high self-efficacy may result in employees putting in less effort to implement change.

Consistent with our predictions based on COR theory (Hobfoll, 1989), the results indicated that trained team leaders acquired the necessary personal resources to deal with demands put on them to implement and manage teams. This was reflected in the significant improvements found in the groups exposed to at least one type of training (supporting Hypotheses 1, 2 and 3).

Our first Hypothesis stated that employee training would facilitate team implementation. The qualitative results indicated that this was mainly the case for the team where no preexisting leader had been present during the intervention and a team member had then taken a leadership role. This finding indicates that training could be especially important when preintervention group structures are heavily disrupted and as a consequence team leaders are new 
to the role during the intervention period. According to SITOL (Hogg, 2001), it is important that leaders and team members share the norms and values concerning teamwork for team members to actively support implementation. Our results suggest that shared mental models existed where the elected team leader and team members had been on the same training course. This research supports previous research suggesting that leaders' participation in team member training supports subordinates' training transfer (Gilpin-Jackson \& Bushe, 2007: Saks \& Belcourt, 2006).

We found some evidence, albeit from only one team, to suggest that team leader training ensured better team implementation (Hypothesis 2). This finding supports COR theory (Hobfoll, 1989) suggesting that providing team leaders with the personal resources to deal with the changed demands of the job enabled the leader to meet these demands and implement teamwork. The team leader reported a strong urge to take charge and drive implementation at the same time as providing a framework for developing social relationships within the team. Interestingly, the team did not experience increased autonomy: the team leader's very directive behavior was revealed by herself and her team in the qualitative data.

It would appear that no one type of training worked better than the other nor that teams where both employees and the team leader received training (group 4) showed the greatest improvements (Hypothesis 3). In this training group, both types of training were perceived positively and as useful interventions. However, only autonomy was perceived to increase. The qualitative analyses suggest that while teams had assumed additional responsibilities there had been few of the team building activities that were seen in groups 2 and 3: the context had been unsupportive and therefore little actual job crafting to implement teamwork structures has been initiated. Our findings correspond with those of Langan-Fox, Code, Gray, and Langfield-Smith (2002) who found that while training did promote individuals' commitment to participation, organizational issues impaired this commitment. The hostile organizational context reported by 
many teams in group 4 makes it difficult to draw firm conclusions about the likely impact of combined training in a stable organizational context. As with previous research our findings indicate the importance of time to use skills learned during training to ensure training transfer (Cromwell \& Kolb, 2004; Gilpin-Jackson \& Bushe, 2007).

Although on the surface the results in group 4 contradict the predictions of SITOL, the contextual factors reported by this group make it difficult to draw firm conclusions on the effectiveness of combined training.

\section{Using Mixed Methods to Understand the Effects of Team Training in Context}

The mixed methods design we used helped us to develop and rule out explanations for the impact of the interventions that would not have been possible in a quantitative quasiexperimental study (Bryman, 2006; 2007). Through triangulation of data we were able to detect changes that had taken place in the groups and develop explanations for quantitative outcomes. In teams where changes were detected in quantitative outcomes, it was also apparent that leaders and employees reported that micro-level changes (e.g. taking on additional responsibilities) had taken place. The qualitative data was used to explore levels below (individuals' mental models) and above (the context) our focal point (the team implementation and the associated training).

The qualitative data were particularly important because our study capitalized on emergent variability in exposure to training. Qualitative methods enabled us to be flexible in exploring competing explanations for differences between conditions that could not be designed out of the study through random allocation of participants and controlled intervention exposure. The advantages of exploring emergent variability in intervention experiences have been identified in several recent intervention studies (Holman, Axtell, Sprigg, Totterdell, \& Wall, 2010; Randall, Griffiths, \& Cox, 2005).

Using Mixed Methods to Answer the How and Why of Intervention Success or Failure 
We argue that using mixed methods in organizational intervention research helps us to directly explain how supporting a teamwork intervention with training can enhance intervention and outcomes. It also showed how the change context and participants' mental models can support (or disrupt) the working mechanisms of teamwork implementation. Together these offer new insights into why teamwork interventions may succeed or fail. As such we provide a way forward for how we may analyze and understand real-life organizational phenomena.

The outcome and process evaluation data combined to show how training helped team members to understand what could be achieved through team organization, and how it helped them to develop personal resources to implement change and provided them with tools and skills to meet the demands of working in teams.

A hostile organizational transfer climate was reported in all groups: Mixed methods allowed us to determine why teamwork was successful in some teams but not others. When leaders' mental models construed a lack of a supportive organizational structure as giving them carte blanche to do what they wish, training appeared to help them and team members to craft teamwork practices even under what might be seen as difficult conditions. This suggestion is consistent with the finding that peer support can facilitate training transfer in a hostile organizational climate that (Martin, 2010). However, our qualitative analyses reveal a significantly more complex picture. In group 4 employees and leaders reported that the organizational context hindered team implementation and this together with the lack of support of some older employees reduced participants' self-efficacy concerning their ability to make changes. This finding is in line with the results of a quantitative study of training transfer (Chiaburu, van Dam, \& Hutchins, 2010) suggesting that generic perceived organizational support is an important determinant of trainees' self-efficacy. In addition, our findings indicate that that participants' mental models of the context determine whether a wider unsupportive organizational context is seen by those affected as an opportunity or as a constraint. 


\section{Theoretical and Practical Implications}

This quasi-experiment contributes to the theoretical knowledge on job crafting, which has primarily been seen as an individual activity (Tims \& Bakker, 2010). Our qualitative analyses reveal how employees who have been made aware of how they can redesign their job within the teamwork framework collectively craft the tasks and relational boundaries of their job. Our findings indicate that interdependency does not prevent job crafting at the group level. Future research should therefore explore the boundaries of collective and individual job crafting and how they interact to influence performance and well-being. Job crafting as a theory appears to help explain why teamwork practices were being implemented or not. In the no-training group, employees and leaders engaged in cognitive job crafting making few attempts to implement teamwork practices. Under the right circumstances training appeared to encourage employees and leaders to engage in relational and task-related job crafting: They initiated working practices that meant they worked jointly towards achieving the team's goals and completing their tasks.

The results of our mixed methods quasi-experiment offer practical information on how organizations can make team implementation succeed (Grant \& Wall, 2009). Team training appears to be a necessary, but not sufficient, supportive initiative when implementing teamwork practices as it provides employees and line managers the necessary personal resources to implement teamwork. When team leaders and employees go on training together, shared mental models may be developed and they hold each other accountable for implementing teams. But training may not be sufficient: The organizational readiness and the mental models of participants, both employees and leaders, should be explored, and if necessary, supportive actions should be taken to prepare the organization and its members for change. We suggest a person should be nominated to take charge to implement the intervention at the team level. This person should be nominated based on his or her positive attitudes towards teamwork. Personal 
resources should be strengthened via training (although it would appear that without a positive mental model of teamwork, training may not have the desired effects). Even teams with selfmanaging characteristics need the support of someone in a leader role when they are forming and stabilizing (Coyle-Shapiro, 1995; Thompson \& Wallace, 1996).

\section{Strengths and Limitations}

The main strengths of this study are its complex, quasi-experimental design (testing three different training groups, with a reference group in a longitudinal design) along with detailed documentation of both intervention outcomes and processes which allowed to us study real-life phenomena thus ensuring external validity. In our process evaluation we were able to compare team leaders' and their employees' mental models to validate our qualitative analysis from both the leader and employee perspectives. In our quantitative analyses, we controlled for pre-test levels on study variables helped to rule out many of the threats to internal validity (Cook \& Campbell, 1979).

There are several limitations that should be considered. First, we used self-report measures in the outcome evaluation. It would have been desirable to also include some objective measures of team effectiveness but because of practical and ethical constraints this was not possible. It is worth noting that team-based interventions generally have more impact on proximal outcome measures (i.e. affective outcomes and team member behaviors) than on distal outcomes with a complex etiology such as team performance (Morgeson et al., 2006). We only included a limited number of proximal outcomes, other team-related characteristics may also change such as clarity of team goals, team motivation and team efficacy are also potentially important outcomes that should be considered in future research.

Second, exposure to training was not randomly allocated but participation was voluntary. This resulted in different group sizes. We argue that for this type of research random assignment would not have been desirable and that the self-selection of participants to into 
intervention groups is an important part of the training process: Randomization create an artificial social situation thus undermining external validity (Grant \& Wall, 2009) and previous training research has indicated that motivation for, and commitment to, training are key factors to its success. Burke and Hutchins (2007) and Blume et al. (2009) found in their meta-analysis that voluntary participation is a predictor of training transfer. A third limitation is that we have very little direct information about the transfer of learning at the individual level (Kraiger, 2003). To partly address this we collected data on reactions to the training courses and the proximal outcomes of training. The qualitative process evaluation also allowed us to examine in details the various mechanisms through which the training had an effect. In this study we had more focus on the effects of transfer on employees' team and work characteristics thus we are unable to identify specific learning points about the content of training.

A fourth limitation concerns the relatively small sample size. Although limiting generalizability, this limitation should be taken in context of the enhanced internal and ecological validity achieved by studying employees and leaders in a functioning work organization. The sample size is quite large compared to other mixed methods studies (Castro, Kellison, Boyd, \& Kopak, 2008). Fifth, the sample was mainly female. The majority of women working in the elder care are female and thus our sample reflects the occupation, however, it would be important to examine the mechanisms in gender-balanced samples to see if results could be replicated. Finally, we used interviews to explore the job crafting behaviors of team members and team leaders to implement team organization. With few exceptions, most of the literature in job crafting is based on qualitative methods (Nielsen \& Abildgaard, 2012; Tims, Bakker, \& Derks, 2012). It would have been desirable to measure job crafting quantitatively to get a representative picture of the levels of job crafting. Although questionnaires on job crafting exist (Lyons, 2008; Nielsen et al., 2012; Tims et al., 2012), to the best of our knowledge there are no questionnaires examining which behaviors 
employees and leaders engage in when implementing teams and it was not within the realm of this study to develop such a questionnaire. The qualitative analyses of job crafting in this study could be used to develop such a questionnaire.

\section{Conclusions}

At the job redesign level, we are able to conclude that while employee and team leader training may facilitate the implementation of teamwork practices, the picture is much more complex as to under which circumstances training is transferred. The mental models of employees and team leaders may either hinder training transfer or help participants craft their jobs implementing teamwork practices. An unsupportive environment can both be perceived as a constraint or an opportunity depending on the mental models of participants. Our results suggest that team mental models play a major role than hitherto anticipated when implementing teamwork practices and has important implications for how organizations should plan team implementation. We were also able to apply psychological theories to explain complex real-life phenomena in the form of complex organizational change processes.

At the methodological level, careful documentation of the implementation processes is needed to understand changes bought about complex, multi-faceted interventions in unpredictable and uncontrolled settings. The mixed methods approach allowed us to strengthen the validity of our results. The unexpected findings would have been inexplicable without the use of qualitative data to examine the mechanisms behind these findings. 


\section{References}

Bambra, C., Egan, M., Thomas, S., Petticrew, \& Whitehead, M. (2007). The psychosocial and health effects of workplace restructuring. 2. A systematic review of task restructuring interventions. Journal of Epidemiology and Community Health, 61, 1028-1037.

Bass, B. M. \& Riggio, R. E. (2006). Transformational leadership. (2nd ed.) Mahwah, NJ: Lawrence Erlbaum.

Blume, B. D., Ford, J. K., Baldwin, T. T., \& Huang, J. L. (2009). Transfer of training: A meta-analytic review. Journal of Management, 36, 1065-1105.

Burke, L. A. \& Hutchins, H. M. (2007). Training transfer: An integrative literature review. Human Resource Development Review, 6, 263-296.

Burke, L. A. \& Saks, A. M. (2009). Accountability in training transfer: Adapting Schlenker's model of responsibility to a persistent and solvable problem. Human Resource Development Review, 8, 382-402.

Bryk, A., Raudenbush, S. (1992). HLM: Applications and data analysis methods. Newbury Park, CA: Sage.

Bryman, A. (2006). Integrating quantitative and qualitative research: how is it done? Qualitative Research, 6, 97-113.

Bryman, A. (2007). Barriers to integrating quantitative and qualitative research. Journal of Mixed Methods Research, 1, 8-22.

Cannon-Bowers, J. A. \& Salas, E. (2001). Reflections on shared cognition. Journal of Organizational Behavior, 22, 195-202. 
Castro, F. G., Kellison, J.G., Boyd, S.J., \& Kopak, A. (2010). A methodology for conducting integrative mixed methods research and data analyses. Journal of Mixed Methods Research, 4, 342-360.

Chiaburu, D. S., van Dam, K., \& Hutchins, H. M. (2010). Social support in the workplace and training transfer: A longitudinal analysis. International Journal of Selection and Assessment, 18, 187-200.

Cohen, S. \& Bailey, D. (1997). What makes teams work: Group effectiveness research from the shop floor to the executive suite. Journal of management, 23, 239-290.

Cook, T. D., \& Campbell, D. T. (1979). Quasi-Experimentation: Design and Analysis for Field Settings. Boston: Houghton Mifflin.

Combs, J., Liu, Y., Hall, A. \& Ketchen, D.( 2006). How much do High-Performance Work Practices matter? A meta-analysis of their effects on organizational performance. Personnel Psychology, 59, 501-528.

Cordery, J., Mueller, W., \& Smith, L. (1991). Attitudinal and behavioral effects of autonomous group working: a longitudinal field study. Academy of Management Journal, 34, 464-476.

Coyle-Shapiro, J. (1995). The impact of TQM intervention to teamwork: a longitudinal assessment. Employee Relations, 17, 63-74.

Creswell, J. W., \& Plano Clark, V. L. (2008). Designing and conducting mixed methods research. Thousand Oaks, CA: Sage.

Cromwell, S. E. \& Kolb, J.A. (2004). An examination of work-environment support factor affecting transfer of supervisory skills training to the workplace. Human Resource Deveopment Quarterly, 15, 449-471. 
Demerouti, E., Bakker, A. B., Nachreiner, F., \& Schaufeli, W. B. (2001). The job demandsresources model of burnout. Journal of Applied Psychology, 86, 499-512.

Druskat, V. U. \& Persocolido, A. T. (2002). The content of effective teamwork mental models in self-managing teams: Ownership, learning and heedful interrelating. Human Relations, 55, 283-314.

Elloy, D. (2005). The influence of superleader behaviors on organization commitment, job satisfaction and organization self-esteem in a self-managed work team. Leadership \& Organizational Development Journal, 26, 120-127.

Freiman, J.A., Chalmers, T.C., Smith, H., Kuebler, R.R. (1978). The importance of beta, the type II error and sample size in the design and interpretation of the randomized control trial - survey of 71 negative trials. New England Journal of Medicine, 299, 690-694.

Fuller, J. B., Marler, L. E., \& Hester, K. (2006). Promoting felt responsibility for constructive change and proactive behavior: Exploring aspects of an elaborated model of work design. Journal of Organizational Behavior, 27, 1089-1120.

Gilpin-Jackson, Y. \& Bushe, G. R. (2007). Leadership development training trasnfer: a case study of post-training determinants. Journal of Management Development, 26, 9801004.

Golhar, D. Y., Deshpande, S. P., \& Ahire, S. L. (1997). Supervisors' role in TQM and nonTQM firms. International Journal of Quality \& Reliability \& Management, 14, $555-$ 568.

Grant, A. M. \& Parker, S. K. (2009). Redesigning work design theories: The rise of relational and proactive perspectives. Academy of Management Annals, 3, 273-331. 
Grant, A. M. \& Wall, T. D. (2009). The neglected science and art of quasi-experimentation: Why-to, when-to, and how-to advice for organizational researchers. Organizational Research Methods, 12, 653-686.

Grossman, R. \& Salas, E. (2011). The transfer of training: what really matters. International Journal of Training and Development, 15, 103-120.

Gurtner, A., Tschan, F., Semmer, N. K., \& Nagele, C. (2007). Getting groups to develop good strategies: Effects of reflexivity interventions on team process, team performance, and shared mental models. Organizational Behavior and Human Decision Processes, 102, 127-142.

Haslam, S.A. \& Platow, M.J. (2001). The link between leadership and followership: How affirming social identity translates vision into action. Personality and Social Psychology Bulletin, 27, 1469-79.

Hobfoll, S. E. (1989). Conservation of resources: A new attempt at conceptualizing stress. American Psychologist, 44, 513-524.

Hogg, M. A. (2001). A social identity theory of leadership. Personality and Social Psychology Review, 5, 184-200.

Holman, D. J., Axtell, C. M., Sprigg, C. A., Totterdell, P., \& Wall, T. D. (2010). The mediating role of job characteristics in job redesign interventions: A serendepitous quasi-experiment. Journal of Organizational Behavior, 31, 84-105.

Johns, G. (2006). The essential impact of context on organizational behavior. Academy of Management Review, 31, 386-408.

Joiner, T. A. (2007). Total quality management and performance: The role of organization support and co-worker support. International Journal of Quality \& Reliability Management, 24, 617-627. 
Kira, M., van Eijnatten, F. M., \& Balkin, D. B. (2010). Crafting sustainable work: development of personal resources. Journal of Management Change, 23, 616-632.

Kozlowski, S. W. J. \& Bell, B. S. (2003). Work groups and teams in organizations. In J. R. Klimoski (Ed.), Handbook of psychology: Industrial and organizational psychology (pp. 333-375). London: Wiley.

Kraiger, K. (2003). Perspectives on training and development. In W.C.Borman, D. R. Ilgen, \& J. R. Klimoski (Eds.), Handbook of psychology: Industrial and organizational psychology (pp. 171-192). Hoboken, NJ: John Wiley \& Sons.

Kristensen, T., Hannerz, H., Hogh, A., \& Borg, V. (2006). The Copenhagen Psychosial questionnaire (COPSOQ). A tool for the assessment and improvement of the psychosocial work environment. Scandinavian Journal of Work and Environmental Health, 31, 438-449.

Langan-Fox, J., Code, S., Gray, R., \& Langfield-Smith, K. (2002). Supporting employee participation: Attitudes and perceptions in trainees, employees and teams. Group Processes \& Intergroup Relations, 5, 53-82.

Leana, C. Appelbaum, E., \& Shevchuk, I. (2009). Work Process and Quality of Care in Early Childhood Education: The Role of Job Crafting. Academy of Management Journal, $52,1169-1192$.

Lyons, P. (2008). The crafting of jobs and individual differences. Journal of Business Psychology, 23, 25-36.

Martin, H. J. (2010). Workplace climate and peer support as determinants of training transfer. Human Resource Development Quarterly, 21, 87-104. 
Mathieu, J. E., Heffner, T. S., Goodwin, G. F., Salas, E., \& Cannon-Bowers, J. A. (2000). The influence of shared mental models on team process and performance. Journal of Applied Psychology, 85, 273-283.

Morgeson, F. P. \& Humphrey, S. E. (2006). The Work Design Questionnaire (WDQ): developing and validating a comprehensive measure for assessing job design and the nature of work. Journal of Applied Psychology, 91, 1321-1339.

Morgeson, F. P., Johnson, M. D., Campion, M. A., Medsker, G. J., \& Mumford, T. V. (2006). Understanding reactions to job redesign: A quasi-experimental investigation of the moderating effects of organizational context on perceptions of performance behavior. Personnel Psychology, 59, 333-363.

Nastasi, B. K., Hitchcock, J., Sarkar, S., Burkholder, G., Varjas, K., \& Jayasena, A. (2007). Mixed methods in intervention research: Theory to adaptation. Journal of Mixed Methods Research, 1, 164-182.

Nielsen, K. \& Abildgaard, J. S. (2012). The validation of a job crafting measure for blue collar workers. Work \& Stress, 26, 365-384.

Nielsen, K. \& Daniels, K. (2012). Enhancing team leaders' daily well-being and proactive behaviors during organizational change: a randomized, controlled study. Human Relations, 65, 1207-1231.

Nielsen, K., Fredslund, H., Christensen, K. B., \& Albertsen, K. (2006). Success or failure? Interpreting and understanding the impact of interventions in four similar worksites. Work \& Stress, 20, 272-287.

Nielsen, K. \& Randall, R. (2013). Opening the black box: a framework for evaluating organizational-level occupational health interventions. European Journal of Work \& Organizational Psychology, 22, 601-616. 
Nielsen, K., Randall, R. \& Christensen, K.B. (2010). A longitudinal field study of the effects of team manager training. Human Relations, 63, 1719-1741.

Noe, R. A., Tews, M. J., \& Dachner, A. M. (2010). Learner engagement: A new perspective for enhancing our understanding of learner motivation and workplace learning. The Academy of Management Annals, 4, 279-315.

Nytrø, K., Saksvik, P. Ø., Mikkelsen, A., Bohle, P., \& Quinlan, M. (2000). An appraisal of key factors in the implementation of occupational stress interventions. Work \& Stress, 14, 213-225.

Osland, A. (1997). Impact of Total quality Management training and work context on attitudes toward supervisor. The International Journal of Organizational Analysis, 5, 291-301.

Parker, S. K., Bindl, U., \& Strauss, K. (2010). Making things happen: A model of proactive motivation. Journal of Management, 36, 827-856.

Parker, S. K. \& Williams, H. (2001). Effective teamworking: Reducing the psychosocial risks. Sudbury, UK: HSE Books.

Patton, M. Q. (2002). Qualitative Research \& Evaluation Methods. Thousand Oaks, CA: Sage.

Petrou, P., Demerouti, E., Peeters, M. C. W., Scahufeli, W. B., \& Hetland, J. (2012). Crafting a job on a daily basis: Contextual correlates and the link to work engagement. Journal of Organizational Behavior, 23, 1120-1141.

Pettigrew, A. M. (1990). Longitudinal field research on change: Theory and practice. Organization Science, 1, 267-292.

Raelin, J. A. (1994). Whither management education? Professional education, action learning and beyond. Management Learning, 25, 301-317. 
Randall, R, Griffiths, A., \& Cox, T. (2005). Evaluating organizational stress management interventions using adapted study designs. European Journal of Work and Organizational Psychology, 14, 23-41.

Rasmussen, T. H. \& Jeppesen, H. J. (2006). Teamwork and associated psychological factors: A review. Work \& Stress, 20, 105-128.

Revans, R. (1971). Developing effective managers: A new approach to business education. London: Longman.

Richardson, K. M., \& Rothstein, H. R. (2008). Effects of occupational stress management intervention programs: A meta-analysis. Journal of Occupational Health Psychology, $13,69-93$.

Saks, A. M. \& Belcourt, M. (2006). An investigation of training activities and transfer of training in organizations. Human Resource Management, 45, 629-648.

Saksvik, P. Ø., Nytrø, K., Dahl-Jørgensen, C., \& Mikkelsen, A. (2002). A process evaluation of individual and organizational occupational stress and health interventions. Work \& Stress, 16, 37-57.

Salas, E., Diaz-Granados, D., Klein, C., Burke, C. S., Stagl, K. C., Goodwin, G. F., \& Halpin, S. M. (2008). Does team training improve team performance? A meta-analysis. Human Factors, 50, 903-933.

Salas, E., Tannenbaum, S. I., Kraiger, K., \& Smith-Jentsch, K. A. (2012). The science of training and development in organizations: What matters in practice? Psychological Science in the Public Interest, 13, 74-101.

Semmer, N. K. (2006). Job stress interventions and the organization of work. Scandinavian Journal of Work and Environmental Health, 32, 515-527. 
Senior, B. \& Swailes, S. (2004). The dimensions of management team performance: a repertory grid study. International Journal of Productivity anbd Performance Management, 53, 317-333.

Smith-Jentsch, K. A., Campbell, G. E., Milanovich, D. M., \& Reynolds, A. M. (2001). Measuring teamwork mental models to support training needs assessment, development, and evaluation: two empirical studies. Journal of Organizational Behavior, 22, 179-194.

Sprigg, C., Jackson, P., \& Parker, S. (2000). Production teamworking: The importance of interdependence and autonomy for employee strain and satisfaction. Human Relations, $53,1519-1543$.

Thomas, J. P., Whitman, D. S., \& Viswesvaran, C. (2010). Employee proactivity in organizations: A comparative meta-analysis of emergent proactive constructs. Journal of Occupational and Organizational Psychology, 83, 275-300.

Thompson, P. \& Wallace, T. (1996). Redesigning production through teamworking: Case studies from the Volvo Truck Corporation. International Journal of Operations and Production Management, 16, 103-116.

Tims, M. \& Bakker, A. B. (2010). Job crafting: Towards a new model of individual job redesign. South African Journal of Industrial Psychology, 36, 1-9.

Tims, M., Bakker, A. B., \& Derks, D. (2012). Development and validation of the job crafting scale. Journal of Vocational Behavior, 80, 173-186.

van Mierlo, H., Rutte, C., Kompier, M., \& Dooreward, H. (2006). Self-managing teamwork and psychological well-being: Review of a multilevel research domain. Group \& Organization Management, 30, 211-235. 
Vancouver, J. B., \& Kendall, L.N. (2006). When self-efficacy negatively relates to motivation and performance in a learning context. Journal of Applied Psychology, 91, 1146-1153.

West, M., Markiewicz, L., \& Dawson, J.F. (2004). TPI: The Team Performance Inventory: User guide. Birmingham, UK: Aston Organisation Development.

Wrzesniewski, A. \& Dutton, J. E. (2001). Crafting a job: Revisioning employees as active crafters of their work. Academy of Management Review, 26, 179-201.

Yeatts, D. E. \& Hyten, C. (1998). High-performing self-managed work teams. California: Sage Publications. 
Table 1: Grouping of teams based on participation in training

\begin{tabular}{|c|c|c|}
\hline Groups & Team member training & Team leader training \\
\hline 1 (5 teams, 112 employees) & No & No \\
\hline 2 (2 teams, 66 employees) & Yes & No \\
\hline 3 (1 team, 26 employees) & No & Yes \\
\hline 4 (6 teams, 124 employees) & Yes & Yes \\
\hline
\end{tabular}

Note. Group 1 is the reference (no training) group. 
Table 2: Multi-level Analyses of Changes over Time. $\mathrm{N}=328$

\begin{tabular}{llllll}
\hline \hline \multirow{2}{*}{ Variable } & Group & $\begin{array}{l}\text { Baseline } \\
\text { Mean }(\mathrm{SD})\end{array}$ & $\begin{array}{l}\text { Follow-up } \\
\text { Mean }(\mathrm{SD})\end{array}$ & Change & CI \\
\hline \hline Interdependency & 1 & $67.8(14.0)$ & $63.2(13.8)$ & -4.33 & $(-10.05 ; 1.39)$ \\
& 2 & $64.4(14.9)$ & $71.5(14.7)$ & $6.83 \dagger$ & $(-0.43 ; 14.10)$ \\
& 3 & $39.2(12.4)$ & $57.2(11.4)$ & $16.56^{*}$ & $(2.51 ; 30.61)$ \\
\hline Autonomy & 4 & $61.6(14.3)$ & $61.9(15.9)$ & 0.27 & $(-5.09 ; 5.63)$ \\
\hline Team & 1 & $65.8(12.1)$ & $66.0(11.0)$ & 0.46 & $(-5.22 ; 6.13)$ \\
effectiveness & 2 & $53.6(13.2)$ & $67.5(14.6)$ & $12.84^{* *}$ & $(4.09 ; 21.58)$ \\
& 3 & $58.0(15.2)$ & $62.1(18.2)$ & 5.08 & $(-6.06 ; 16.21)$ \\
& 4 & $57.3(20.1)$ & $63.3(15.9)$ & $5.29 \dagger$ & $(-0.24 ; 10.82)$ \\
\hline Involvement & 1 & $55.2(19.8)$ & $48.5(16.8)$ & $-6.72 *$ & $(-13.35 ;-0.10)$ \\
& 3 & $49.0(16.4)$ & $60.6(18.0)$ & $11.89^{* * *}$ & $(3.19 ; 20.59)$ \\
& 2 & $38.9(18.8)$ & $53.8(20.9)$ & $14.58 \dagger$ & $(-2.09 ; 31.25)$ \\
& 4 & $55.1(19.1)$ & $50.9(18.4)$ & -4.30 & $(-10.59 ; 1.99)$ \\
\hline \hline
\end{tabular}

$\overline{\text { Note. Controlled for baseline team levels. Group } 1=\text { reference group, group } 2=\text { employee }}$ training only, group $3=$ team leader training only, group $4=$ both team leader and employee training.

$\dagger=\mathrm{p}<.10, *=\mathrm{p}<.05, * *=\mathrm{p}<.01, * * *=\mathrm{p}<.001 . \mathrm{CI}=$ Confidence Interval 